\title{
Eighth-Line Therapy
}

National Cancer Institute

\section{Source}

National Cancer Institute. Eighth-Line Therapy. NCI Thesaurus. Code C133529.

Treatment that is given when the first seven treatments don't work, or stop working. 